\title{
Fluorescent "light-up" bioprobes based on tetraphenylethylene derivatives with aggregation-induced emission characteristics $\dagger$
}

\author{
Hui Tong, ${ }^{a}$ Yuning Hong, ${ }^{a}$ Yongqiang Dong, ${ }^{a b}$ Matthias Häußler, ${ }^{a}$ Jacky W. Y. Lam, ${ }^{a}$ Zhen Li, ${ }^{a}$ \\ Zufeng Guo, ${ }^{a}$ Zhihong Guo ${ }^{a}$ and Ben Zhong Tang*ab
}

Received (in Cambridge, UK) 14th June 2006, Accepted 10th July 2006

First published as an Advance Article on the web 2nd August 2006

DOI: $10.1039 / \mathrm{b} 608425 \mathrm{~g}$

Aggregation in poor solvents and complexation with calf thymus DNA and bovine serum albumin turn "on" the fluorescence of tetraphenylethylene derivatives, due to the restriction of intra-molecular rotations of the dyes in the aggregates and complexes.

The study of detection of biomacromolecules by fluorescence (FL) probes is emerging as an active area of research due to its potential applications in biological science and engineering. ${ }^{1}$ The FL-based technique offers high sensitivity, low background noises, and wide dynamic ranges. ${ }^{2}$ Upon complexation with proteins and DNAs, FL of the bioprobes can be enhanced/quenched and/or red/blueshifted, thus enabling visual observation of the biomacromolecular species. The most useful bioprobes are those "turn-on" sensors, whose FL is activated by analytes. ${ }^{3}$ Several probes for DNA detection based on FL enhancement have been developed, such as phenanthridine and acridine derivatives. ${ }^{4}$ FL enhancements induced by proteins have been reported for fluorescamine, $O$ phthaldialdehyde, NanoOrange, SYPRO, and Nile Red. ${ }^{5}$ FL intensities of cyanine and acridizinium dyes have been found to increase dramatically upon complexation with DNA and proteins. ${ }^{6}$ Water-soluble "light-up" probes for the detection of biomacromolecules such as DNAs and proteins are, however, still rare.

Many FL dyes aggregate when dispersed in aqueous media or bound to biological polymers in large quantities. Self-quenching often accompanies the aggregation of the dyes, resulting in drastic reductions in their FL signals. This aggregation-caused quenching (ACQ) has been a thorny problem in the development of efficient bioprobes and biosensors. ${ }^{7}$ Recently, we and others have observed a phenomenon exactly opposite to the ACQ, that is, aggregationinduced emission (AIE): some nonemissive dyes can be induced to emit efficiently by the aggregate formation. ${ }^{8-10}$ AIE molecules with high quantum yields ( $\Phi_{\mathrm{F}}$ up to 0.85 ) and various emission colors (blue, green, yellow and red) have been reported. ${ }^{8,9}$ While the AIE dyes have been used for the construction of efficient optical and

${ }^{a}$ Department of Chemistry, The Hong Kong University of Science \& Technology, Clear Water Bay, Kowloon, Hong Kong, China. E-mail: tangbenz@ust.hk; Fax:+852-2358-1594;Tel:+852-2358-7375 ${ }^{b}$ Department of Polymer Science and Engineering, Zhejiang University, Hangzhou 310027, China

$\dagger$ Electronic supplementary information (ESI) available: preparation and characterization details for dyes $\mathbf{1 - 4}$; absorption, emission and excitation spectra of their aggregate suspensions and biopolymer complexes; effects of solution concentration and solvent viscosity on their photophysical properties; and temperature dependence of ${ }^{1} \mathrm{H}$ NMR spectra of $\mathbf{1}$ and associated $\ln \delta_{\text {fwhm }} v s$ 1/T plot. See DOI: $10.1039 / \mathrm{b} 608425 \mathrm{~g}$ photonic devices, ${ }^{11}$ the possibility of employing them as bioprobes for detecting biopolymers have been virtually unexplored. ${ }^{12}$ In this work, we synthesized a group of AIE-active tetraphenylethylene (TPE) derivatives 1-4 (Chart 1) and examined the utility of watersoluble cationic salts $\mathbf{3}$ and $\mathbf{4}$ as bioprobes. In the aqueous buffer solutions, these non-emissive fluorophores become highly emissive upon binding to protein and DNA molecules through noncovalent, such as hydrophobic and electrostatic, interactions.

The TPE derivatives were prepared by the synthetic route shown in Scheme S1 (ESI $\dagger$ ). Reactions of 1,2-bis(4-hydroxyphenyl)-1,2-diphenylethene with $\alpha, \omega$-dibromoalkanes in the presence of sodium hydride yielded TPEs $\mathbf{1}$ and $\mathbf{2}$, whose quaternizations by $\mathrm{NEt}_{3}$ gave salts 3 and 4, respectively. Molecular structures of the TPEs were characterized by spectroscopic techniques, from which satisfactory analysis data were obtained (ESI $\dagger$ ). Dyes $\mathbf{1}$ and $\mathbf{2}$ are soluble in common organic solvents such as acetonitrile (AN), chloroform and THF but insoluble in water. Salts $\mathbf{3}$ and $\mathbf{4}$, on the other hand, are soluble in water as well as DMF and DMSO.

Dilute solutions of $\mathbf{1}$ and $\mathbf{2}$ in AN are practically nonluminescent. Addition of nonsolvent water into the AN solutions can turn on the emissions of the dyes. From the molecular solution in AN to the aggregate suspension in an $\mathrm{AN}$-water mixture (1: 99 by volume), the FL intensity of 1 at $476 \mathrm{~nm}$ is increased by $\sim 240$ fold (Fig. 1A). Its absorption maximum shifts from $310 \mathrm{~nm}$ in the solution to $330 \mathrm{~nm}$ in the suspension. The excitation maximum of 1 locates at $330 \mathrm{~nm}$ (Fig. S1, ESI $\dagger$ ), coinciding well with its absorption maximum. The formation of nanoscopic aggregates of $\mathbf{1}$ is suggested by the level-off tail in the visible region of its absorption spectrum due to the Mie effect of the nanoparticles. ${ }^{13}$ Evidently, the emission of $\mathbf{1}$ is induced by the aggregate formation, or in other words, $\mathbf{1}$ is AIE-active.

The change of $\Phi_{\mathrm{F}}$ value of $\mathbf{1}$ with water fraction in the $\mathrm{AN}-$ water mixture further reveals its AIE characteristics (Fig. 1B). In the mixtures with water fractions below $\sim 40 \%, 1$ exhibits negligibly small $\Phi_{\mathrm{F}}$ values $(\sim 0.5 \%$, ESI $\dagger)$ because the dye molecules are genuinely dissolved in the mixtures. The $\Phi_{\mathrm{F}}$ value of 1 starts to increase when the water fraction is increased to

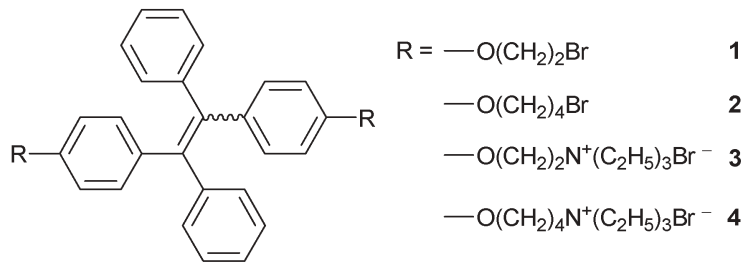

Chart 1 Structures of tetraphenylethene derivatives 1-4. 

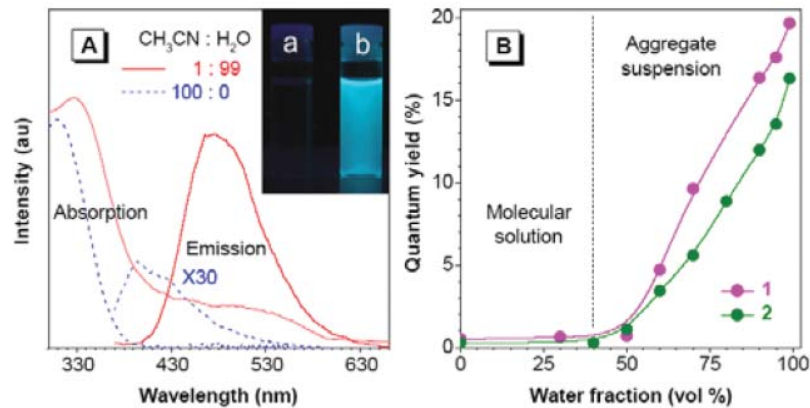

Fig. 1 (A) Absorption and emission spectra of solutions of $\mathbf{1}(10 \mu \mathrm{M})$ in AN and AN-water mixture (1: $99 \mathrm{v} / \mathrm{v})$. Inset: Photographs of solutions of 1 in (a) AN and (b) the AN-water mixture taken under illumination of a UV lamp. (B) Dependence of fluorescence quantum yields of solutions of $\mathbf{1}$ and $\mathbf{2}$ on the solvent composition of $\mathrm{AN}-$ water mixture. $\lambda_{\mathrm{ex}}=350 \mathrm{~nm}$.

$\sim 50 \%$, at which the solvating power of the mixture is worsened to such an extent that the dye molecules begin to aggregate. The $\Phi_{\mathrm{F}}$ value reaches $\sim 20 \%$ at a water content of $99 \%$, which is $\sim 40$-fold higher than that of its AN solution. The absolute $\Phi_{\mathrm{F}}$ values of the aggregates should be much higher than the relative $\Phi_{\mathrm{F}}$ values given in Fig. 1B, because the determination of the latter did not take into consideration the strong absorption caused by the Mie effect of the aggregates. $^{14}$

Dye 2 shows similar AIE behaviours (Table S1 and Fig. S3, ESI $\dagger$ ). Salts $\mathbf{3}$ and $\mathbf{4}$ are soluble in water. Addition of methanol, $\mathrm{AN}, \mathrm{THF}$ and dioxane to their water solutions cannot cause the salts to aggregate, possibly due to their amphiphilic nature. Their emissions in the mixtures remain as faint as those in the water solutions. However, increasing the concentrations of the salts can increase their $\Phi_{\mathrm{F}}$ values, implying that the salts are also AIE-active (Fig. S3, ESI $\dagger$ ).

Complexation of the water-soluble AIE dyes with calf thymus (ct) DNA and bovine serum albumin (BSA) were investigated by spectrometric titrations in aqueous phosphate buffer $(\mathrm{pH}=7.0)$ at $25^{\circ} \mathrm{C}$. Stock solutions of $\mathbf{3}$ and $\mathbf{4}(0.25 \mathrm{mM})$ were prepared (ESI $\dagger$ ). The mixture of $100 \mu \mathrm{L}$ stock solution of $\mathbf{3}$ with $9.9 \mathrm{~mL}$ buffer emits faintly at $395 \mathrm{~nm}$ with a side band at $462 \mathrm{~nm}$ (Fig. S4, ESI†). Its absorption maximum locates at $311 \mathrm{~nm}$, with a molar absorptivity of $12400 \mathrm{M}^{-1} \mathrm{~cm}^{-1}$. Upon addition of the DNA, FL intensity of 3 is increased by 5.4 fold. Meanwhile its emission maximum shifts to $\sim 462 \mathrm{~nm}$, giving a Stokes shift as large as $134 \mathrm{~nm}$. In the DNA concentration range of $0-100 \mu \mathrm{g} \mathrm{mL}^{-1}$, the plot of the FL intensity (I) at $462 \mathrm{~nm}$ as a function of DNA concentration $(c)$ is a linear line with a correlation coefficient of 0.996. Addition of BSA to buffer solution of $\mathbf{3}$ induces a similar effect. The linear range of the $I / I_{\mathrm{O}}-1$ vs. $c$ plot in this case is $0-50 \mu \mathrm{g} \mathrm{mL} \mathrm{m}^{-1}$. The excitation maximums of the solutions of $\mathbf{3}$ containing BSA and ct DNA both locate at $328 \mathrm{~nm}$ (Fig. S5, ESI $\dagger$ ).

The effects of the biopolymers on the FL properties of $\mathbf{4}$ are much more pronounced. As can be seen from Fig. 2, $I / I_{\mathrm{O}}$ values as high as 16.3 and 23.8 are achieved when $300 \mu \mathrm{g} \mathrm{mL}^{-1}$ ct DNA and $500 \mu \mathrm{g} \mathrm{mL}^{-1}$ BSA are added into the solutions of 4 , respectively. Clearly $\mathbf{4}$ is a more sensitive bioprobe. The excitation maximum is at $328 \mathrm{~nm}$ and the Stokes shift is $\sim 135 \mathrm{~nm}$. The linear ranges of $\mathbf{4}$ are narrower: $0-20 \mu \mathrm{g} \mathrm{mL}^{-1}$ for DNA and $0-40 \mu \mathrm{g} \mathrm{mL}^{-1}$ for BSA. It now becomes obvious that the AIE salts $\mathbf{3}$ and $\mathbf{4}$ can be
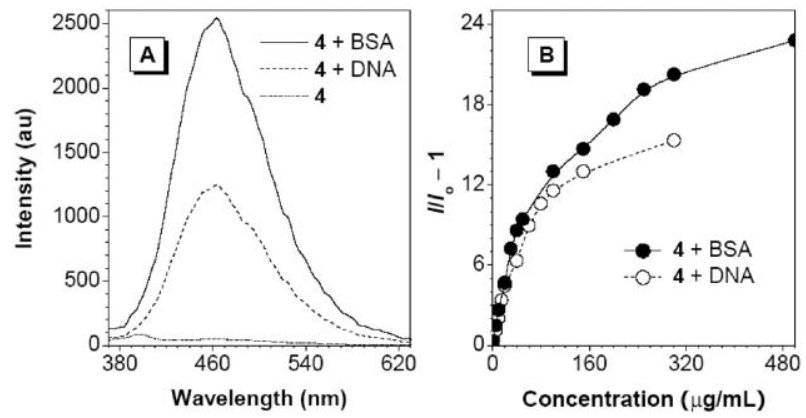

Fig. 2 (A) Emission spectra of $4(2.5 \mu \mathrm{M})$ in an aqueous phosphate buffer $(\mathrm{pH}=7)$ and in the buffers containing $300 \mu \mathrm{gL}^{-1}$ ct DNA and $500 \mu \mathrm{g} \mathrm{mL}{ }^{-1}$ BSA. (B) Plots of fluorescence intensities of buffer solutions of 4 at $463 \mathrm{~nm} v s$. concentrations of ct DNA and BSA.

used as light-up bioprobes for DNA and protein detection. The probing sensitivity and linear range can be tuned by modifying their structures.

Regarding the origin of the emission induced by the addition of the biomacromolecules, the correlation with the AIE nature of the dyes must be considered. In both cases, similar shifts in the FL maximums (from $390-399 \mathrm{~nm}$ to $463-478 \mathrm{~nm}$ ) are observed. The excitation spectra of the biopolymer-induced emissions are also similar to those of the AIEs for the TPE derivatives. These facts lead to a natural conclusion that the strong blue emissions are from the same excited species.

We have proposed that the restriction of intramolecular rotations in the aggregates of AIE dyes may have blocked their nonradiative channels, thus making them highly emissive. ${ }^{15}$ If the AIE process of the TPE dyes follows the same mechanism, they should become emissive in the solutions with high viscosities at low temperatures, because under these conditions their intramolecular rotations would be hampered. The FL behaviours of $\mathbf{4}$ were thus investigated in a highly viscous glycerol-water (99: 1 by volume) mixture at different temperatures. At $25{ }^{\circ} \mathrm{C}$, the glycerol-water solution of 4 emits a strong blue light of $467 \mathrm{~nm}$ with a Stokes shift of $147 \mathrm{~nm}$ (Fig. 3), demonstrating that the high viscosity indeed helps. As the solution temperature is decreased from 25 to $-5^{\circ} \mathrm{C}$, the FL intensity of $\mathbf{4}$ is increased just as expected. Its excitation maximum locates at $328 \mathrm{~nm}$ (Fig. S6, ESI $\dagger$ ), close to those of its nanoscopic aggregates and its complexes with the biopolymers.

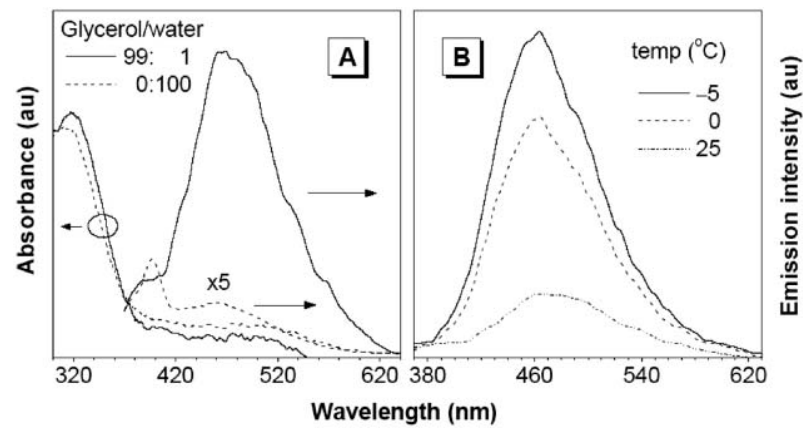

Fig. 3 (A) Absorption and emission spectra of $4(2.5 \mu \mathrm{M})$ in water and a glycerol-water mixture at $25^{\circ} \mathrm{C}$. (B) Emission spectra of $4(2.5 \mu \mathrm{M})$ in glycerol-water ( $99: 1$ by volume) mixture at different temperatures. 
It is well known that fast conformational exchanges caused by fast intramolecular rotations give sharp NMR resonance peaks, which can be broadened by cooling because the rotations and hence the exchanges become slower at lower temperatures. ${ }^{16}$ Dynamic NMR experiments of a dichloromethane solution of $\mathbf{1}$ reveals that its resonance peaks are broadened with a decrease in temperature (Fig. S7, ESI $\dagger$ ). The plot of $\ln \delta_{\text {fwhm }} v s .1 / T$ gives a linear line (Fig. S8, ESI†), suggesting a single mechanism for the peak broadening. All these results confirm that the restriction of intramolecular rotations plays a crucial role in the AIE process.

We now may conjure up the picture of how the emissions of the TPE salts are turned on by the addition of the biomacromolecules. In the buffer solutions containing the DNA and BSA, the cationic amphiphilic dyes bind to the biomacromolecules via noncovalent interactions, such as electrostatic attraction (especially for the negative-charged DNA) and hydrophobic effect (particularly for the protein with hydrophobic pockets in its native folding structure). When docked on the surfaces of the biopolymers and in the cavities of their folding structures, the dye molecules aggregate with the aid of strong electronic and hydrophobic interactions between their aryl rings. This suppresses intramolecular rotations of the dye molecules, which in turn impedes their radiationless transitions and activates their FL processes. Thanks to the AIE nature, the emissions of the TPE-biopolymer complexes are greatly intensified with increasing concentration, as can be seen from the example given in Fig. S9 (ESI $\dagger$ ) for the 4 BSA complex. This is truly remarkable, because conventional FL probes suffer from the ACQ problem at high dye concentrations. ${ }^{7}$

In summary, in this work, we have successfully developed AIEactive, water-soluble, cationic dyes for protein and DNA detection in the aqueous media for the first time. The non-emissive dye solutions become emissive upon addition of the DNA and BSA. These AIE dyes exhibit large molar absorptivities, high quantum yields and wide Stokes shifts and are thus ideal "turn-on" FL bioprobes. The restriction of their intramolecular rotations is believed to play a critical role in their AIE processes. We envision that any molecule whose electronic conjugation is affected by the twisting of multiple pendants around its core due to involved steric effects can be AIE active. This work opens a wide avenue for utilizing AIE luminophors as FL probes in the area of biological research. Further studies of other AIE dyes with green, yellow and red emissions for detecting biological species are currently under way in our laboratories.

This project was partially supported by the Hong Kong Research Grants Council (602706, HKU2/05C, 603505, 603304 and 664903) and the Ministry of Science \& Technology (2002CB613401). B.Z.T. thanks the Cao Guangbiao Foundation of Zhejiang University.

\section{Notes and references}

1 (a) M. W. Peczuh and A. D. Hamilton, Chem. Rev., 2000, 100, 2479; (b) W. C. Tse and D. L. Boger, Acc. Chem. Res., 2004, 37, 61; (c) I. L. Medintz, H. T. Uyeda, E. R. Goldman and H. Mattoussi, Nat. Mater., 2005, 4, 435.

2 (a) A. P. deSilva, H. Q. N. Gunaratne, T. Gunnlaugsson, A. J. M. Huxley, C. P. McCoy, J. T. Rademacher and T. E. Rice, Chem. Rev., 1997, 97, 1515; (b) W. P. Ambrose, P. M. Goodwin, J. H. Jett,
A. Van Orden, J. H. Werner and R. A. Keller, Chem. Rev., 1999, 99, 2929; (c) W. F. Patton, Biotechniques, 2000, 28, 944.

3 (a) H. Tong, L. X. Wang, X. B. Jing and F. S. Wang, Macromolecules, 2003, 36, 2584; (b) A. Basak, S. S. Bag and A. Basak, Bioorg. Med. Chem., 2005, 13, 4096; (c) G. Y. Ma, A. M. Muller, C. J. Bardeen and Q. Cheng, Adv. Mater., 2006, 18, 55; (d) L. J. Fan and W. E. Jones, J. Phys. Chem. B, 2006, 110, 7777.

4 (a) M. D. Dutton, R. J. Varhol and D. G. Dixon, Anal. Biochem., 1995, 230, 353; (b) G. Malojcic, I. Piantanida, M. Marinic, M. Zinic, M. Marjanovic, M. Kralj, K. Pavelic and H. J. Schneider, Org. Biomol. Chem., 2005, 3, 4373.

5 (a) J. R. Daban, S. Bartolome and M. Samso, Anal. Biochem., 1991, 199, 169; (b) X. P. Li, K. Abdi and S. J. Mentzer, J. Immunol. Methods, 1994, 172, 141; (c) T. H. Steinberg, L. J. Jones, R. P. Haugland and V. L. Singer, Anal. Biochem., 1996, 239, 223; (d) L. J. Jones, R. P. Haugland and V. L. Singer, Biotechniques, 2003, 34, 850; (e) Y. Suzuki and K. Yokoyama, J. Am. Chem. Soc., 2005, 127, 17799.

6 (a) A. Mishra, R. K. Behera, P. K. Behera, B. K. Mishra and G. B. Behera, Chem. Rev., 2000, 100, 1973; (b) S. M. Yarmoluk, D. V. Kryvorotenko, A. O. Balanda, M. Y. Losytskyy and V. B. Kovalska, Dyes Pigm., 2001, 51, 41; (c) A. Granzhan and H. Ihmels, Org. Lett., 2005, 7, 5119.

7 J. B. Birks, Photophysics of Aromatic Molecules, Wiley, London, 1970.

8 (a) J. Luo, Z. Xie, J. W. Y. Lam, L. Cheng, H. Chen, C. Qiu, H. S. Kwok, X. Zhan, Y. Liu, D. Zhu and B. Z. Tang, Chem. Commun., 2001, 1740; (b) J. Chen, Z. Xie, J. W. Y. Lam, C. C. W. Law and B. Z. Tang, Macromolecules, 2003, 36, 1108; (c) C. C. W. Law, J. Chen, J. W. Y. Lam, H. Peng and B. Z. Tang, J. Inorg. Organomet. Polym., 2004, 14, 39; (d) Y. Q. Dong, J. W. Y. Lam, Z. Li, H. Tong, Y. P. Dong, X. D. Feng and B. Z. Tang, J. Inorg. Organomet. Polym. Mater., 2005, 15, 287; (e) Z. Li, Y. Q. Dong, Y. H. Tang, M. Häußler, H. Tong, Y. P. Dong, J. W. Y. Lam, K. S. Wong, P. Gao, I. D. Williams, H. S. Kwok and B. Z. Tang, J. Phys. Chem. B, 2005, 109, 10061; (f) H. Tong, Y. Q. Dong, M. Haussler, J. W. Y. Lam, I. D. Williams, J. Sun and B. Z. Tang, Chem. Commun., 2006, 1133; (g) H. Tong, Y. Q. Dong, M. Häußler and B. Z. Tang, Mol. Cryst. Liq. Cryst., 2006, 446, 183.

9 (a) B. K. An, S. K. Kwon, S. D. Jung and S. Y. Park, J. Am. Chem. Soc., 2002, 124, 14410; (b) S. Jayanty and T. P. Radhakrishnan, Chem.Eur. J., 2004, 10, 791; (c) H. J. Tracy, J. L. Mullin, W. T. Klooster, J. A. Martin, J. Haug, S. Wallace, I. Rudloe and K. Watts, Inorg. Chem., 2005, 44, 2003; (d) Z. Wang, H. Shao, J. Ye, L. Tang and P. Lu, J. Phys. Chem. B, 2005, 109, 19627; (e) S. J. Toal, K. A. Jones, D. Magde and W. C. Trogler, J. Am. Chem. Soc., 2005, 127, 11661; (f) K. Itami and J. Yoshida, Chem.-Eur. J., 2006, 12, 3966; $(g)$ M. R. Han and M. Hara, New J. Chem., 2006, 30, 223; (h) H. Wang, D. Pang, H. Xin, M. Li, P. Zhang and W. Tian, Liq. Cryst., 2006, 33, 439; (i) C. J. Bhongale and C. S. Hsu, Angew. Chem., Int. Ed., 2006, 45, 1404. 10 (a) J. Chen, B. Xu, X. Ouyang, B. Z. Tang and Y. Cao, J. Phys. Chem. A, 2004, 108, 7522; (b) C. J. Bhongale, C.-W. Chang, C.-S. Lee, E. W.-G. Diau and C.-S. Hsu, J. Phys. Chem. B, 2005, 109, 13472; (c) G. Yu, S. Yin, Y. Liu, J. Chen, X. Xu, X. Sun, D. Ma, X. Zhan, Q. Peng, Z. Shuai, B. Z. Tang, D. Zhu, W. Fang and Y. Luo, J. Am. Chem. Soc., 2005, 127, 6335.

11 (a) H. Chen, W. Y. Lam, J. Luo, Y. Ho, B. Z. Tang, D. Zhu, M. Wong and H. S. Kwok, Appl. Phys. Lett., 2002, 81, 574; (b) B. Mi, Y. Q. Dong, Z. Li, J. W. Y. Lam, M. Häußler, H. S. Kwok, Y. P. Dong, Y. Liu, I. D. Williams, Y. Luo, Z. Shuai, D. Zhu and B. Z. Tang, Chem. Commun., 2005, 3583; (c) S. H. Lee, B. B. Jang and Z. H. Kafafi, J. Am. Chem. Soc., 2005, 127, 9071.

12 C. P.-Y. Chan, M. Häußler, B. Z. Tang, Y. Q. Dong, K. Sin, W.-C. Mak, D. Trau, M. Seydack and R. Renneberg, J. Immunol. Methods, 2004, 295, 111.

13 B. Z. Tang, Y. Geng, J. W. Y. Lam, B. Li, X. Jing, X. Wang, F. Wang, A. Pakhomov and X. X. Zhang, Chem. Mater., 1999, 11, 1581.

14 All the absolute quantum yields $\left(\Phi_{\mathrm{F}, \mathrm{a}}\right)$ of the AIE-active siloles are higher than their relative ones $\left(\Phi_{\mathrm{F}, \mathrm{r}}\right)$ : for example, $\Phi_{\mathrm{F}, \mathrm{a}}$ of 1-methylpentaphenylsilole $(85 \%)^{10 \mathrm{c}}$ is $\sim 4$-fold higher than its $\Phi_{\mathrm{F}, \mathrm{r}}(21 \%)^{8 \mathrm{a}}$.

15 J. Chen, C. C. W. Law, J. W. Y. Lam, Y. P. Dong, S. M. F. Lo, I. D. Williams, D. Zhu and B. Z. Tang, Chem. Mater., 2003, 15, 1535.

16 J. Sandstrom, Dynamic NMR Spectroscopy, Academic Press, London, UK, 1982. 